\title{
Shaping ability of ProTaper Gold in preparation of moderate curved canals (in vitro study)
}

\author{
E. Radeva ${ }^{1}$, R. Radev ${ }^{2}$, M. Maznev ${ }^{2}$, Ts.Uzunov ${ }^{1}$ \\ ${ }^{1}$ Department of Conservative Dentistry, Faculty of Dental Medicine, MU-Sofia, Bulgaria \\ ${ }^{2}$ Students, Faculty of Dental Medicine, MU-Sofia, Bulgaria \\ DOI: 10.29322/IJSRP.11.08.2021.p11664 \\ http://dx.doi.org/10.29322/IJSRP.11.08.2021.p11664
}

\begin{abstract}
Introduction: The presence of a curve limits the preparation of the root canal and can lead to procedural errors related with the formation of ledges, fracture of instruments, canal transportation or perforation of the apical foramen. NickelTitanium instruments are recommended to use in such cases due to their superior flexibility and resistance to cyclic fatigue. Aim: To assess the shaping ability of ProTaper Gold in preparation of moderate curved canals $\left(25^{\circ}-30^{\circ}\right)$ on extracted human teeth, using x-ray. Materials and methods: The experimental study was performed on extracted human teeth (canines, premolars and lower molars, $n=24$ canals). Diagnostic radiographs were done in order to determine the root canal curvature beforehand. The teeth that were used had moderate curvature of $25^{\circ}-30^{\circ}$. The coronal part of the teeth was removed using diamond burrs and the root length was standardized at $15 \mathrm{~mm}$ (using visual method). The root canals were prepared using ProTaper Gold up to F3. After preparation diagnostic radiographs were made to evaluate the results reduction of working length, fracture of instruments, ledges and perforations. The data obtained was statistically processed. Results: Reduction of working length by $0.27 \pm 0.05 \mathrm{~mm}$ was observed. During the preparation stage of the root canals using ProTaper Gold no breakage of any instrument was observed. No ledges or perforations were formed. Conclusions: Following the results of this in vitro study it can be concluded that the use of ProTaper Gold instruments facilitates the preparation of moderately curved root canals. This can be attributed to their superior physical properties which allow better preservation of the original shape of the root canal.
\end{abstract}

Index Terms- moderate curved canals, ProTaper Gold, radiograph assessment, shaping ability

\section{INTRODUCTION}

$\mathrm{T}$ The preparation of the root canal is an important step in the endodontic treatment. The presence of a curvature limits the preparation and can lead to procedural errors related with the formation of ledges, fracture of instruments, canal transportation or perforation of the apical foramen [1,2]. Also in curved root canals, disinfection of the entire root canal presents a difficulty.

In cases of curved root canals it is recommended to use NickelTitanium instruments due to their superior flexibility and resistance to cyclic fatigue. Different studies confirm that they can maintain canal centering $[3,4]$.
Several Ni-Ti systems have been described in many studies. ProTaper system is one of them and consist of instruments which have progressively variable tapers and during the root canal preparation worked in vertical and horizontal directions. They have convex triangular cross-sections, and noncutting tips. ProTaper instruments work with crown-down technique $[4,5]$.

ProTaper Gold system uses CM wire technology and because of this has higher flexibility and resistance to cyclic fatigue compere to Pro Taper Universal [6].

The aim of the presented study is to assess shaping ability of Nickel-Titanium rotary instruments ProTaper Gold in preparation of moderate curved canals $\left(25^{\circ}-30^{\circ}\right)$ on extracted human teeth, using $\mathrm{x}$-ray to establish reduction of working length, fracture of instruments, ledges and perforations

\section{MATERIALS AND METHODS}

The experimental study was performed on extracted human teeth (canines, premolars and lower molars, $\mathrm{n}=24$ canals). Diagnostic radiograph was done in order to determine the root canal curvature beforehand.

Three methods were used to determine the root canals' curvatures (fig. 1 a, b, c), based on the Schneider method (Fig. 2) - three points are used which are marked in the region of the orifice, the canal deflection and the apical foramen. After connecting the first and second points, a line is created and a second line is drawn after the second and third points are joined. The curvature is determined by the angle between them.

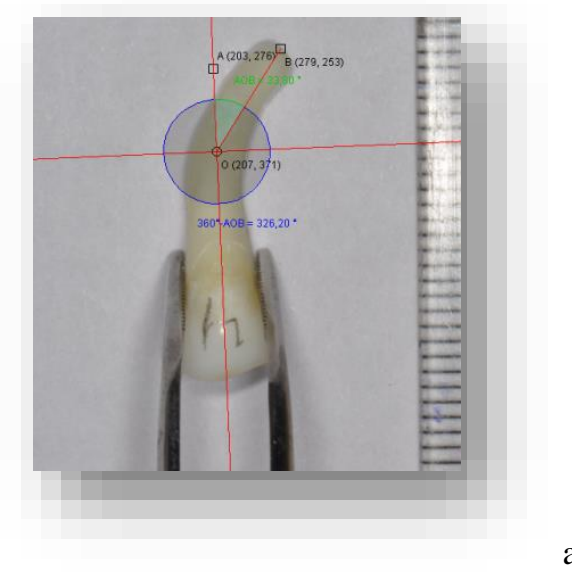



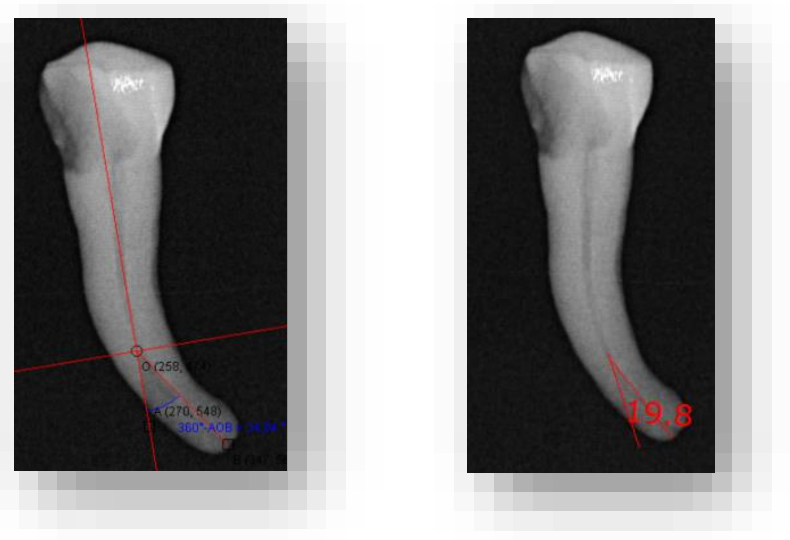

b

$\mathrm{c}$

Fig. 1: Determining the curvature of the root canals via:

a) A new digital photographic method and special software (Screen Protractor)

b) A new digital $X$-ray method and special software (Screen Protractor)

c) An approved digital method by X-ray and Special Software (Duerr Dental)

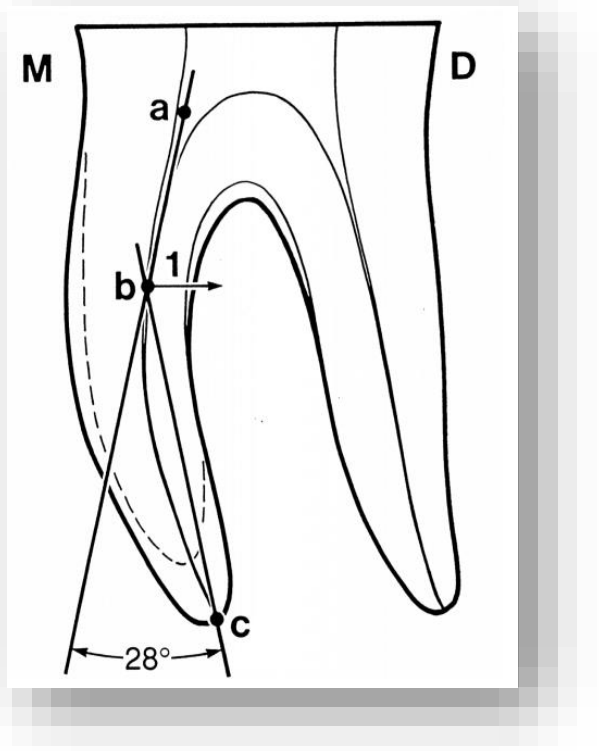

Fig. 2: The Schneider method for determining a root's curvature

The teeth that were used had moderate curvature of $25-30^{\circ}$. The coronal part of the teeth was removed using a diamond bur (Fig. $3 \mathrm{c}$ and $4 \mathrm{c}$ ) and the root length was standardized at $15 \mathrm{~mm}$ using a visual method. K-file \#10 was inserting to the apical foramen until the tip of the file was visible, after that the length was reduce with $1 \mathrm{~mm}$ shorter from this measurement.

The root canals were prepared using ProTaper Gold up to F3 (Fig. 3). The files were used according manufacturer instruction. The coronal third was drilled with Sx ProTaper Gold with brushing motion. With pre - banding hand K-files \#10 was checked the patency of the canals. The root canal preparation was continue using the shaping files S1 and S2, which are use at working length (WL). These instruments have D0 diameters $0.17 \mathrm{~mm}$ and $0.20 \mathrm{~mm}$ with a flute diameter of $1.20 \mathrm{~mm}$. ProTaper Gold S1 and S2 have variable increasing tapers over the length of their cutting blades. The progressively tapered allows each instrument to touch a specific area on the middle and coronal thirds of the root canal. After shaping files the preparation was continued using finishing files F1 (D0-0.20), F2 (D0-0.25) until F3 (D00.30 ) at working length. The finishing files have decreasing tapers along their lengths and remove the dentine in the apical third of the canal. Irrigation solution $1 \mathrm{ml}$ of $5.25 \% \mathrm{NaOCl}$ with needle $27 \mathrm{G}$ was used between each file and recapitulation with hand Kfiles in the corresponding size. After preparation, a final irrigation protocol was followed with $3 \mathrm{ml}$ of $5.25 \% \mathrm{NaOCl}, 3 \mathrm{ml}$ of saline and $2 \mathrm{ml}$ of $17 \%$ EDTA.

After cleaning and shaping of the root canals, radiographs were made to evaluate the results - reduction of working length, fracture of instruments, ledges and perforations. The data obtained was statistically processed. 


\section{RESULTS}

The initially determined working length (WL) was compared to the length after preparation of the root canals to F3 using
ProTaper Gold (Fig. 3). A smaller reduction between the initial and the final WL was observed $-0.27 \pm 0.05 \mathrm{~mm}$.

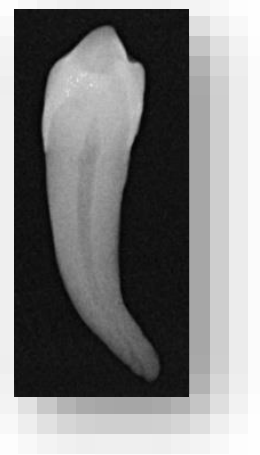

a

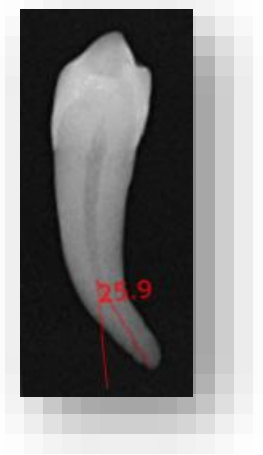

b

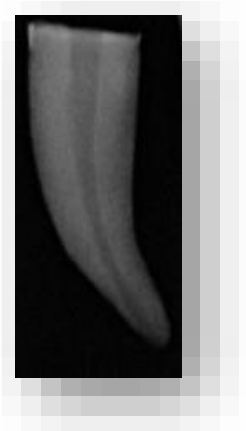

c

Fig. 3: Radiographs of premolar

a) A diagnostic radiograph done before the study.

b) Determining the root canal curvature using Durr Dental Software.

c) A radiograph after the coronal part was removed and the canals were shaped by ProTaper Gold up to F3 file.

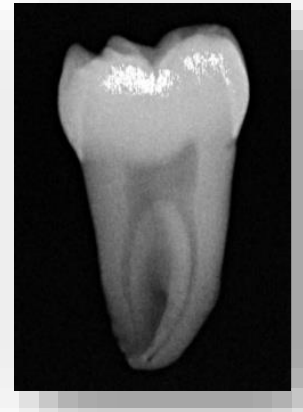

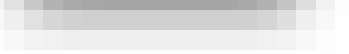

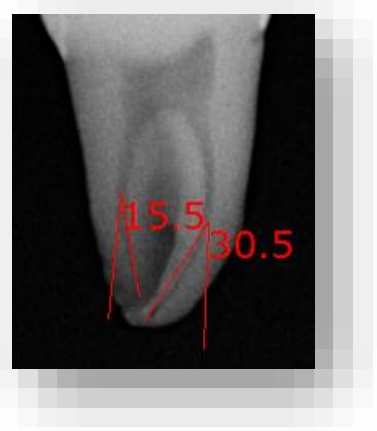

$\mathrm{b}$

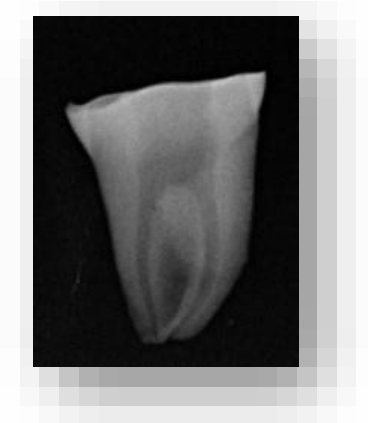

Fig.4:Radiographs of molar

a) A diagnostic radiograph done before the study.

b) Determining the root canal curvature using Durr Dental Software.

c) A radiograph after the coronal part was removed and the canals were shaped by ProTaper Gold up to F3 file.

During the preparation stage of the moderate curved root canals $(n=24)$ using ProTaper Gold no breakage of any instrument was observed on the X-ray. No ledges or perforations were formed (Fig. 3c and Fig. 4c).

\section{DISCUSSION}

The complex root canal anatomy and curved canals can lead of procedural errors during root canal cleaning and shaping [2, 7]. Nickel-titanium rotary instruments used in the last two decades reduce the fatigue of operator, time for root canal preparationhas and minimized procedural errors $[8,9]$

The loss of working length is one of many possible instrumentation errors. Krajczár K. et al compare the loss of working length after preparation with steel hand K-files and nickel-titanium MTwo rotary instruments. Loss of $0.2 \mathrm{~mm}$ of the working length is established after preparation of the root canal. The results show that with the increase of the size of the preparation instrument at the apical zone, the risk of working length loss also increases [8]. In the current study we concluded that preparation of moderately curved canals using F3 files of the
ProTaper Gold system resulted in loss of working length of 0.27 $\mathrm{mm}$.

Park H. also determine that nickel-titanium instruments are better at following the original root canal shape, compared to stainless steel instruments. In their study, GT files have shown a slight enlargement over instrumentation toward the inner side in the beginning of curvature [10].

Faraj B. determines that there is no statistically significant difference between the diagnostic and postinstrumental working length when using files with reciprocating rotation such as WaveOne Gold [11].

Other errors in the preparation of curved root canals can be strip perforation, ledge formation, apical transportation, fracture of instruments. The use of nickel-titanium instruments reduces the risk of these errors and leads to better centering and following the original shape of the root canal $[3,4,10]$. In our study during the preparation stage of the root canals using ProTaper Gold no 
breakage of any instrument was observed. No ledges or perforations were formed.

According to the manufacturer ProTaper Gold have increased flexibility, have resistance to cyclic fatigue and follow the original shape of the canals. Arslan H. et al establish that there is no statistically significant difference between transportation and canal centering at levels of $3 \mathrm{~mm}, 5 \mathrm{~mm}$ and $7 \mathrm{~mm}$ between ProTaper Gold, ProTaper Universal and Reciproc during preparation in severely curved toot canals [3].

Gagliardi J. et al. in their study concluded that the ProTaper Gold has less transportation from the original root canal shape than the ProTaper Universal in moderately curved $\left(25^{\circ}-35^{\circ}\right)$ canals of lower molars [4]. Our results confirm their conclusions.

\section{CONCLUSIONS}

Following the results of this in vitro study, it can be concluded that the use of ProTaper Gold instruments facilitates the preparation of moderately curved root canals. This can be attributed to their superior physical properties that allow better preservation of the original shape of the root canal.

\section{ACKNOWLEDGEMENTS}

The study was funded under contract D-88/03.05.2018 to Medical University - Sofia

\section{REFERENCES}

[1] Patnana A., Chugh A. Endodontic Management of Curved Canals with ProTaper Next: A Case Series. Contemp Clin Dent 2018, 9(1):168-172

[2] Chisamera S., Diaconu F., Dascalu I., Bataiosu M., Anghel A., Moraru I., Rica A., Tuculina J. Comparative study on root canal therapy preparation with rotating tools ProTaper Gold and HyFlex. Journal of Dental and Medical Sciences, 2017, 16(6):98-103

[3] Arslan H., Yildiz E., Gunduz H., Sumbulu Meltem., Bayrakdar I., Karatas E., Sumbullu Muhammed. Comparative study of ProTaper Gold, Reciproc and ProTaper Universal for root canal preparation in severely curved root canals. J Conserv Dent, 2017, 20(4): 222-224

[4] Gagliardi J., Versiani M., Dammiao de Sousa-Neto M., Plazas-Garzan A., Basrani B. Evaluation of the shaping characteristics of ProTaper Gold, ProTaper Next and ProTaper Universal in curved canals. J of Endodontics, 2015, 41(10): 1718-1724

[5] www.dentsplaysirona.com

[6] Duque J., Vivan R., Cavenago B, Amoroso-Silva P, Bernardes R., Vasconcelos B., Duarte M. Influence of NiTi alloy on the root canal shaping capabilities of the ProTaper Universal and ProTaper Gold rotary instrument systems. J Appl Sci, 2017,25(1):27-33

[7] Elnaghy A., S. Elsaka. Shaping ability of proTaper Gold and ProTaper Universal files by using cone-beam computed tomography. Indian Journal of Dental Research, 2016, 27(1):37-41

[8] Krajczar K., Varga E., Marada G., Jeges S., Toth V. Comparison of working length control consistency between hand K-files and Mtwo NiTi rotary system. Journal of Clinical and experimental Dentistry, 2016, 8(2):136-140

[9] Mamede-Neto I., Borges A., Alencar A., Duarte M., Sousa-Neto, Estrela C. Multidimensional analysis of curved root canal preparation using continuous or reciprocating Nickel-titanium instruments. Open Dental J. 2018, 12:32-45

[10] Park H. A comparison of Greater Taper files, ProFiles, and stainless steel files to shape curved root canals. Oral Surg Oral Med Oral Pathol Oral Radiol Endod. 2001;91:715-8

[11] Faraj B. Root canal curvature as a prognostic factor influencing the diagnostic accuracy of radiographic working length determination and postoperative canal axis modification: an in vitro comparative study. BMC Oral Health 2021, 21(1):90. doi: 10.1186/s12903-021-01446-x

\section{AUTHORS}

First Author - Elka Nikolaeva Radeva, Associate Professor, Department of Conservative Dentistry, Faculty of Dental Medicine, Medical University, Sofia, Bulgaria, e-mail: eliradeva@abv.bg 